\title{
Giant chondroid lipoma of the breast: A case report and literature review
}

\author{
ADNAN AL ALOUL ${ }^{1,2}$, SILVIU SAVGA ${ }^{1}$, CAMELIA DIACONU ${ }^{3,4}$, CORNEL SAVU $^{5,6}$, \\ OVIDIU STIRU $^{7,8}$, MIHAI DIMITRIU ${ }^{9,10}$, IRINA BALESCU ${ }^{11}$ and NICOLAE BACALBASA ${ }^{9,12,13}$
}

\begin{abstract}
${ }^{1}$ Department of Surgery, Ramnicu Sarat County Hospital, 125300 Ramnicu Sarat; ${ }^{2}$ Department of Surgery, Titu Maiorescu University, 040051 Bucharest; ${ }^{3}$ Department of Internal Medicine, 'Carol Davila' University of Medicine and Pharmacy, 020021 Bucharest; ${ }^{4}$ Department of Internal Medicine, Clinical Emergency Hospital of Bucharest,

105402 Bucharest; ${ }^{5}$ Department of Thoracic Surgery, 'Carol Davila' University of Medicine and Pharmacy, 020021 Bucharest; ${ }^{6}$ Department of Thoracic Surgery, 'Marius Nasta' Institute of Pneumology, 050159 Bucharest; ${ }^{7}$ Department of Cardiovascular Surgery, 'Carol Davila' University of Medicine and Pharmacy, 020021 Bucharest; ${ }^{8}$ Department of Cardiovascular Surgery, 'Prof. Dr. C.C. Iliescu' Emergency Institute for Cardiovascular Diseases, 022322 Bucharest; ${ }^{9}$ Department of Obstetrics and Gynecology, 'Carol Davila' University of Medicine and Pharmacy, 020021 Bucharest; ${ }^{10}$ Department of Obstetrics and Gynecology, 'Sf. Pantelimon' Emergency Clinical Hospital, 021659 Bucharest; ${ }^{11}$ Department of Visceral Surgery, 'Ponderas' Academic Hospital, 021188 Bucharest; ${ }^{12}$ Department of Visceral Surgery, Center of Excellence in Translational Medicine, 'Fundeni' Clinical Institute, 022328 Bucharest;

${ }^{13}$ Department of Obstetrics and Gynecology, 'I. Cantacuzino' Clinical Hospital, 030167 Bucharest, Romania
\end{abstract}

Received April 20,2021; Accepted May 20, 2021

DOI: $10.3892 / \mathrm{etm} .2021 .10521$

\begin{abstract}
Chondroid lipoma is a rare benign lesion affecting the breast, in which the diagnosis of malignancy is difficult to be excluded during preoperative studies. In this respect, a correct histopathological diagnosis is mandatory in order to avoid overdiagnosis and subsequently overtreatment. In the present study, the case of a 61-year-old patient who self-referred for the development of a large tumor at the level of the left breast is reported. Biopsy raised the suspicion of a chondroid lipoma; thus, the patient was submitted to conservative surgery. The lesion was completely excised by performing a total mastectomy. The histopathological studies confirmed the presence of chondroid lipoma, with no signs of malignant transformation. At the 24-month follow-up interval no signs of recurrence were detected. In conclusion, although it may reach significant dimensions, giant chondroid lipoma of the breast is a benign lesion that may benefit from conservative treatment and does not recur.
\end{abstract}

Correspondence to: Dr Irina Balescu, Department of Visceral Surgery, 'Ponderas' Academic Hospital, 85a Nicolae Caramfil Street, 021188 Bucharest, Romania

E-mail: irina.balescu@ponderas-ah.ro

Abbreviations: BIRDAS, breast imaging-reporting and data system

Key words: giant chondroid lipoma, differential diagnosis, surgery, breast surgery

\section{Introduction}

Although lipoma is the most commonly encountered benign mesenchymal tumor (1), chondroid lipoma is a rare entity originating from soft tissues that was initially described by Meis and Enzinger in 1993 (1). Due to the presence of certain similarities with extra-skeletal chondrosarcoma and round cell liposarcoma, the diagnosis of this pathological entity may become challenging especially in cases presenting large lesions $(2,3)$. Histopathological and immunohistochemical studies demonstrating the presence of an association between adipose tissue, cartilaginous tissues, mature adipocytes, chondroblasts and hyaline matrix as well as the absence of aberrant proliferation suggesting malignant transformation seems to play a crucial role in order to provide a differential diagnosis with malignant lesions such as chondrosarcoma and liposarcoma (4). Providing a correct diagnosis is crucial in the prevention of the overtreatment of these lesions which otherwise may be treated as malignant lesions.

In the present study, the case of a 61-year-old patient who self-referred for the development of a large tumor at the level of the left breast is reported.

\section{Case report}

Patient data. A 61-year-old patient with no significant medical history self-presented for the appearance of a large tumor which was observed within the last eight months and which presented a rapid growth within the last three months.

The clinical examination revealed the presence of a large tumoral mass having developed at the level of the left breast 

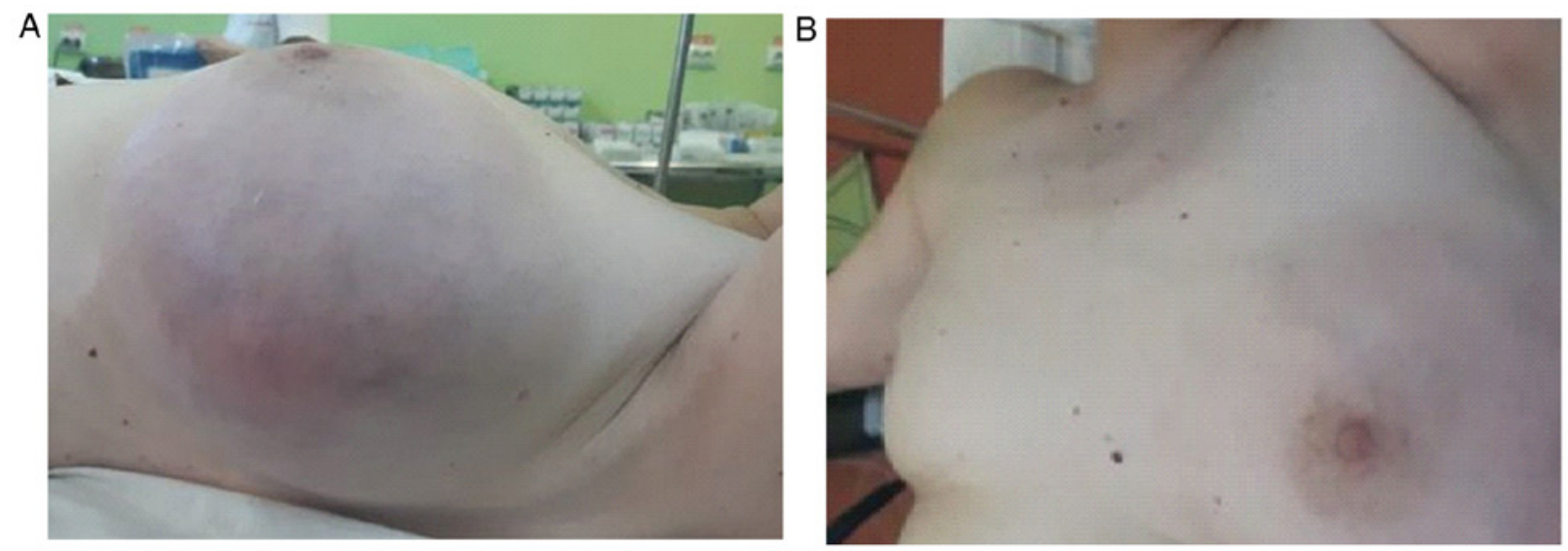

Figure 1. (A) Initial preoperative procedure. The entire breast is deformed by the presence of a large tumoral mass inducing the apparition of collateral circulation. (B) Initial preoperative procedure: The whole breast is deformed by the presence of a large tumoral mass while the nipple presents no significant modifications.

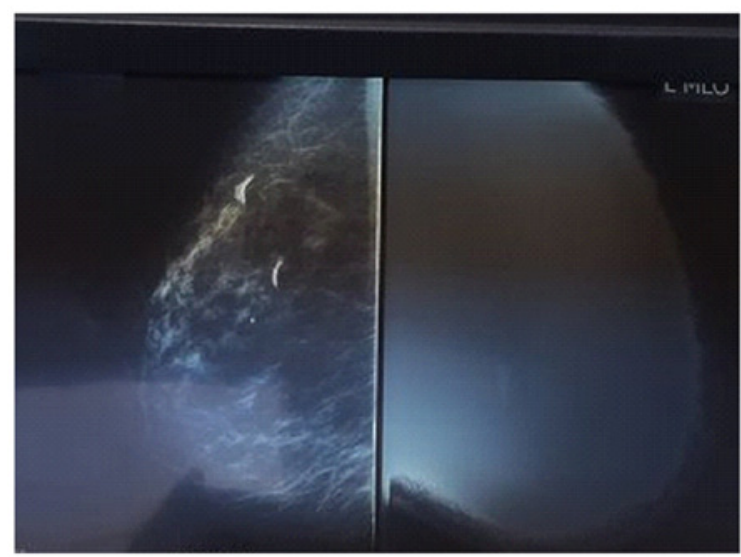

Figure 2. Mammography shows the presence of multiple calcifications.

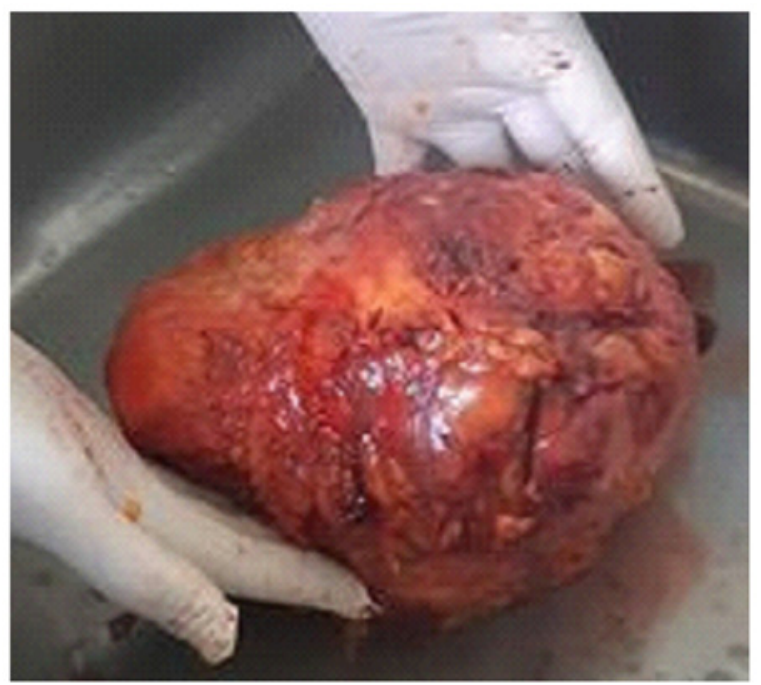

Figure 3. The specimen, obtained from total mastectomy, is a large, encapsulated tumor.

measuring $20 / 15 \mathrm{~cm}$, deforming the entire breast. Additionally, signs of collateral circulation were observed at the level of the adjacent skin (Fig. 1). The mass seemed to keep its mobility in the surrounding skin and to the prepectoral fascia while the

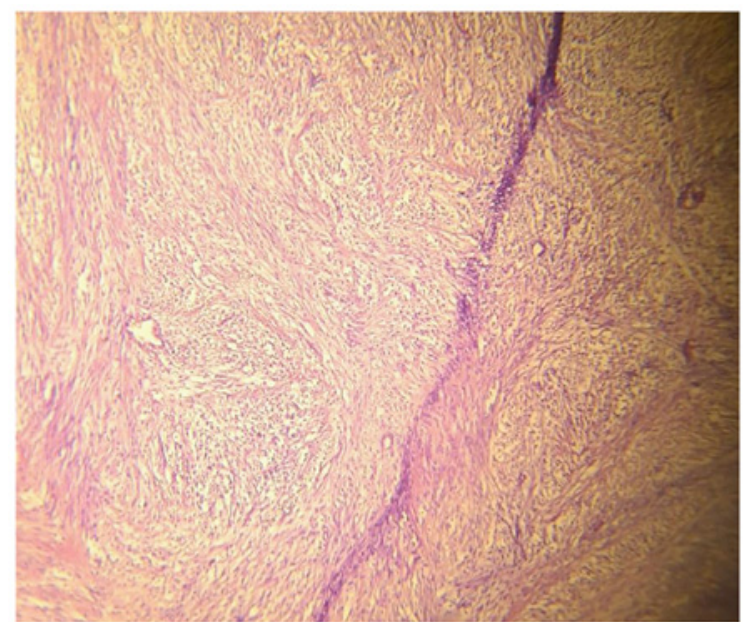

Figure 4. Histopathological studies included hematoxylin and eosin staining. Magnification, $x 10$. Mature adipose tissue and many cartilaginous islands and mixoid cells are noted.

nipple presented no pathological aspects and no discharge. Local examination of the left axilla failed to demonstrate the presence of suspect adenopathies; furthermore, the contralateral breast and axilla presented no pathological modifications (Fig. 1A and B).

Methods. The patient was further submitted to a mammography which confirmed the presence of a $22 / 18 \mathrm{~cm}$ lesion with regular margins and intra-tumoral calcifications. The lesion was classified as a Breast Imaging-Reporting and Data System (BIRDAS) grade 2 tumor, and normal breast parenchyma was almost absent (Fig. 2). The patient underwent breast ultrasound which confirmed the presence of a heterogeneous mass measuring 20/18/15 cm with peripheral positive Doppler signal and minimal areas of normal breast parenchyma; the ultrasound-guided biopsy raised the suspicion of a chondroid lipoma, with no signs of malignancy being encountered. The patient then underwent surgery with conservative intent; however, after excision of the encapsulated tumor, no remnant breast parenchyma was found. Therefore, total mastectomy was performed (Fig. 3). The histopathological studies, which 
included hematoxylin and eosin staining, demonstrated the presence of a 20/18/10 cm encapsulated lesion presenting mesenchymal proliferation formed by chondroid myxoid matrix with lipoblast areas and blood vessels and no mitotic activity (Fig. 4). In addition, a $1.5 \mathrm{~cm}$ fibroadenoma was also found in the close proximity of the giant chondroid lipoma. The postoperative outcome was uneventful. The patient then underwent breast reconstruction with an implant two months later. At 24 months, the patient is free of local or distant recurrent disease.

\section{Discussion}

The structure of breast lipomas is usually modified by the presence of other mesenchymal elements leading to the development of fibrolipoma, angiolipoma, osteolipoma, myxolipoma, or chondrolipoma (5). Most often cartilaginous transformation inside a lipomatous lesion leading to the development of a chondrolipoma is related to a prolonged evolution and to larger dimensions of a lipoma (6). Although the exact process of chondrolipoma histogenesis is not well understood, there are three theories which have been considered. The first one considers that in cases in which glandular components are found inside the tumor, they act like choristoma; the second theory considers that immature mesenchymal cells develop towards both adipocytes and chondrocytes; while the third theory considers that these tumors originate from cartilaginous metaplasia of the adipose tissue in lipomas (7-13).

Chondroid lipomas are delimited, asymptomatic lesions developed in the subcutaneous tissues or at the level of the skeletal muscles, more commonly at the level of the arms, neck and head. Breast chondroid lipomas represent a scarce eventuality, being more frequently encountered in young women (during the third decade of life) and present as small volume lesions (2). Their histopathological particularity is represented by the presence of cartilaginous tissue among mature fat and glandular mammary parenchyma and their dimensions usually range between 2 and $6 \mathrm{~cm}$ (4). Giant lesions are those

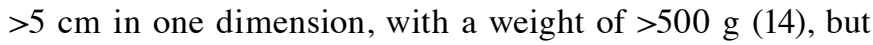
rarely surpassing $10 \mathrm{~cm}$ (15). The tumor is characterized by the presence of peripheral compressed mammary parenchyma which is transformed into a true capsule for the tumor while at the level of the tumor ductal structures and mammary stroma may not be present $(4,16)$. In order to achieve proper diagnosis, imagistic studies such as breast ultrasound, mammography, and MRI followed by biopsy is mandatory. When it comes to the mammographic aspect of the lesion, it usually presents as a radiolucent mass due to the presence of an increased amount of fatty tissue in the absence of mammary stroma or ducts in association with focal opacities induced by the presence of islets of cartilaginous structures. However, the presence of calcifications is rather scarce, with few such cases being reported thus far $(5,7,17)$. Therefore, preoperatively, in the absence of a biopsy, the differential diagnosis with a malignant lesion is rather difficult to be established $(5,18)$. The most common entities which should be taken into consideration when performing a differential diagnosis are represented by fat necrosis, giant fibroadenoma, supernumerary breast as well as malignant lesions such as chondrosarcoma or liposarcoma (15-28); in this respect, ultrasound-guided biopsy is mandatory.

Thus, appropriate diagnosis of benignity can be established and therefore, the patient can be submitted to local excision of the lesion, and overtreatment can be prevented (4,14,29-36). However, in certain cases, due to the high volume of the lesion, retrieving the tumor can consist in fact in performing a total mastectomy (as presented in our case) although surgery is not intended to be a radical one as long as the biopsy has confirmed the absence of atypical mitoses (3). In order to prevent the risk of local recurrence, complete excision of the lesion en bloc with the adjacent capsule is mandatory $(4,15)$.

Another important aspect which should be taken into consideration when it comes to chondroid lipoma of the breast is the one regarding the differential diagnostic with malignant chondroid tumors such as primary chondroid sarcoma (19-24). Therefore, in cases in which malignant transformation is suspected, immunohistochemical studies aiming to investigate the presence of cytokeratin expression are mandatory (25-28).

In summary, giant breast chondroid lipoma represent scarce situations affecting women worldwide. Preoperative biopsy is mandatory in order to demonstrate the absence of any sign of malignant disease and to further allow the surgeon to perform tumoral enucleation without radical breast surgery. However, in certain cases the absence of normal breast parenchyma will transform the enucleation procedure into a total mastectomy followed by breast reconstructive surgery.

\section{Acknowledgements}

Not applicable.

\section{Funding}

No funding was received.

\section{Availability of data and materials}

Further information regarding the case study is available from the corresponding author on reasonable request.

\section{Authors' contributions}

AAA and SS performed the surgical procedures. NB, MD and IB prepared the draft of the article in light of the literature data and case findings. NB was advisor of the surgical procedures. $\mathrm{CD}, \mathrm{CS}$ and OS preoperatively investigated the patient. AAA and NB revised the final draft of the manuscript. All authors read and approved the final manuscript.

\section{Ethics approval and consent to participate}

The Ethics Committee of Ramnicu Sarat County Hospital approved the study (no. 21/2018).

\section{Patient consent for publication}

Written informed consent was obtained from the patient on 11.04.2018. 


\section{Competing interests}

The authors declare that they have no competing interests.

\section{References}

1. Meis JM and Enzinger FM: Chondroid lipoma. A unique tumor simulating liposarcoma and myxoid chondrosarcoma. Am J Surg Pathol 17: 1103-1112, 1993.

2. Vandeweyer E and Scagnol I: Axillary giant lipoma: A case report. Acta Chir Belg 105: 656-657, 2005.

3. Aljarrah A, Malik KA, Al Jarraha A, Sawhney S and Lakhtakia R Chondroid lipoma of breast: A rare pathology. J Liaquat Univ Med Health Sci 12: 131-132, 2013.

4. Banev SG and Filipovski VA: Chondrolipoma of the breast-case report and a review of literature. Breast 15: 425-426, 2006.

5. Sudhamani S, Pandit AA and Kiri VM: Chondrolipoma of breast: A case report with the review of the literature. J Sci Soc 39: 147-148, 2012

6. Weiss SW and Goldblum JR: Cartilaginous soft tissue tumors In: Enzinger and Weiss's Soft tissue tumors. 4th edition. Strauss M (ed).St. Louis, Mosby, p1361, 2001

7. Kaplan L and Walts AE: Benign chondrolipomatous tumor of the human female breast. Arch Pathol Lab Med 101: 149-151, 1977.

8. Benisch B, Peison B and Sarno J: Benign mesenchymoma of the breast. Mt Sinai J Med 43: 530-533, 1976.

9. Fushimi H, Kotoh K, Nishihara K, Fujinaka H and Takao T: Chondrolipoma of the breast: A case report with cytological and histological examination. Histopathology 35: 478-479, 1999.

10. Fujimura $\mathrm{N}$ and Enomoto S: Lipoma of the tongue with cartilaginous change: A case report and review of the literature. J Oral Maxillofac Surg 50: 1015-1017, 1992.

11. Lugo M, Reyes JM and Putong PB: Benign chondrolipomatous tumors of the breast. Arch Pathol Lab Med 106: 691-692, 1982.

12. Katzer B: Histopathology of rare chondroosteoblastic metaplasia in benign lipomas. Pathol Res Pract 184: 437-445, 1989.

13. Shintaku M, Yamamoto Y, Kono F, Kitai T, Tsuji W, Yotsumoto $F$ and Kushima R: Chondrolipoma of the breast as a rare variant of myofibroblastoma: An immunohistochemical study of two cases. Virchows Arch 471: 531-535, 2017.

14. Ricardo CR, Renato S, Luiz F and Espana Q: Breast reconstruction with parenchymal cross after giant lipoma removal. Aesth Plast Surg 32: 695-697, 2008.

15. Jorwekar GJ, Baviskar PK, Sathe PM and Dandekar KN: Giant chondroid lipoma of breast. Indian J Surg 74: 342-343, 2012.

16. Marsh WL Jr, Lucas JG and Olsen J: Chondrolipoma of the breast. Arch Pathol Lab Med 113: 369-371, 1989.

17. Perez MT and Alexis JB: Chondrolipoma of the breast presenting as calcifications in a routine mammogram. Histopathology 35 189-191, 1999.

18. Stark AM and Sunter JP: Benign chondrolipomatous tumour of the breast. Clin Radiol 39: 328-329, 1988

19. Errarhay S, Fetohi M, Mahmoud S, Saadi H, Bouchikhi C and Banani A: Primary chondrosarcoma of the breast: A case presentation and review of the literature. World J Surg Oncol 11: 208 , 2013.

20. Nakanishi G, Lin SN, Asagoe K, Suzuki N, Matsuo A, Tanaka R, Makino E, Fujimoto W and Iwatsuki K: A novel fusion gene of collagen type 1 alpha 1 (exon 31 ) and platelet derived growth factor B-chain( exon 2) in dermato fibrosarcome protuberans. Eur J Dermatol 17: 217-219, 2007.
21. Montgomery E, Goldblum JR and Fisher C: Myofibrosarcoma: A clinicopathologic study. Am J Surg Pathol 25: 219-228, 2001.

22. Morgan PB, Chundra S, Hatch SS, Hawkins HK, Adegboyega PA and Eltorky MA: Uncommon malignancies: Case 1. Low grade myofibroblastic sarcoma of the breast. J Clin Oncol 23: 6249-6251, 2005

23. Stark M, Hoffman A and Xiong Z: Mammary myofibrosarcoma: Case report and literature review. Breast J 17: 300-304, 2011

24. Brenn T and Fletcher CD: Radiation-associated cutaneous atypical vascular lesions and angiosarcoma: Clinicopathologic analysis of 42 cases. Am J Surg Pathol 29: 983-996, 2005.

25. Cooper R, Rajak R, Valentine K and Bhargava V: Metaplastic carcinoma of the breast. Diagnostic Histopathol 24: 83-85, 2018

26. Ginter PS, Mosquera JM, MacDonald TY, D'Alfonso TM, Rubin MA and Shin SJ: Diagnostic utility of MYC amplification and anti-MYC immunohistochemistry in atypical vascular lesions, primar yor radiation induced mammary angiosarcoma and primary angiosarcomas of other sites. Hum Pathol 45: 709-716, 2014.

27. Cornejo KM, Deng A, Wu H, Cosar EF, Khan A, Cyr MS, Tomaszewicz K, Dresser K, O'Donnell P and Hutchinson L: The utility of MYC and FLT4 in the diagnosis and treatment of post radiation atypical vascular lesion and angiosarcoma. Hum Pathol 46: 868-875, 2015

28. Maggiano F, Debiec-Rychter M, Vanbockrijck M and Sciot R: Cellular angiofibroma: Another mesenchymal tumour with 13q14 involvement, suggesting a link with spindle cell lipoma and (extra)-mammary myofibroblastoma. Histopathology 51: 410-412, 2007

29. Pasta V, Sottile D, Urciouli P, Del Vecchio L, Custureri F and D'Orazi V: Rare chondrosarcoma of the breast treated with quadrantectomy instead of mastectomy: A case report. Oncol Lett 9: 1116-1120, 2015.

30. Pasta V, Monti M, Cialini M, Vergine M, Urciuoli P, Iacovelli A, Rea S and D'Orazi V: Primitive sarcoma of the breast: New insight on the proper surgical management. J Exp Clin Cancer Res 34: 72, 2015

31. Thilagavath G, Subramanian S, Samuel AV, Rani U and Somasundaram C: Primary chondrosarcoma of the breast. J Indian Med Assoc 90: 16-17, 1992.

32. Vandenhaute B, Validire $P$, Veillex $C$, Voelh $P$ and Zafrani B: Breast carcinoma with chondroid metaplasia. Ann Pathol 15: 53-58, 1995.

33. Pencavel TD and Hayes A: Breast sarcoma-a review of diagnosis and management. Int J Surg 7: 20-23, 2009.

34. Pasta V, Monti M, Antonucci D, Di Matteo FM, Boccaccini F and Brescia A: Primary sarcoma of the breast: Criteria for radical surgery. G Chir 18: 703-706, 1997.

35. Stojadinovic A, Leung DH, Hoos A, Jaques DP, Lewis JJ and Brennan MF: Analysis of the prognostic significance of microscopic margins in 2,084 localized primary adult soft tissue sarcomas. Ann Surg 235: 424-434, 2002.

36. Zelek L, Llombart-Cussac A, Terrier P, Pivot X, Guinebretiere JM, Le Pechoux C, Tursz T, Rochard F, Spielmann $\mathrm{M}$ and Le Cesne A: Prognostic factors in primary breast sarcomas: A series of patients with long-term follow-up J Clin Oncol 21: 2583-2588, 2003. 